\title{
Severe megaloblastic anemia in twin pregnancy mimicking partial hemolysis, elevated liver enzymes and low platelet count syndrome: a case report
}

\author{
S. Momon Singh ${ }^{1}$, Vaidehi Thakur ${ }^{2}$, P. Manisana Singh ${ }^{3 *}$
}

\author{
${ }^{1}$ Department of Obstetrics and Gynecology, INHS Sanjivani, Kochi, Kerala, India \\ ${ }^{2}$ Department of Obstetrics and Gynecology, NH Powai, Maharashtra, India \\ ${ }^{3}$ Department of Plastic Surgery, RIMS Imphal, Manipur, India
}

Received: 28 September 2021

Accepted: 28 October 2021

\author{
*Correspondence: \\ Dr. P. Manisana Singh, \\ E-mail: singhmomon@gmail.com
}

Copyright: (C) the author(s), publisher and licensee Medip Academy. This is an open-access article distributed under the terms of the Creative Commons Attribution Non-Commercial License, which permits unrestricted non-commercial use, distribution, and reproduction in any medium, provided the original work is properly cited.

\begin{abstract}
Vitamin B12 is well known cause of megaloblastic anemia. However, it is uncommon in pregnancy, occurs in $10-28 \%$ of uncomplicated pregnancies, and is associated with few complications. Present case of 32 years old woman with twinpregnancy at late gestation who was diagnosed with severe anemia in a local private clinic. On arrival to medical center, lab findings together with her clinical picture warranted the concern for differential diagnosis of partial hemolysis, elevated liver enzymes and low platelet count (HELLP), but later it was found to be a case of vitamin B12 deficiency since additional lab findings. Blood transfusions were given, and patient responded well to B12 supplementation. Pregnancy was carried to term and delivered twin live babies but otherwise well at birth and had normal developmental milestones thereafter. Our case emphasizes the importance of screening for B12 deficiency in pregnancy, especially in at-risk women (twin-pregnancy in pure vegetarian women) with unexplained anemia/r thrombocytopenia.
\end{abstract}

Keywords: Vitamin B12, Megaloblastic anemia, Laboratory, HELLP, Twin pregnancy, Thrombocytopenia

\section{INTRODUCTION}

Anemia during pregnancy is common and has both maternal and foetal consequences. ${ }^{1}$ The most common cause is iron deficiency anemia; other causes include infection, folate and vitamin B12 deficiency. ${ }^{1,2}$ Anemia specifically caused by B12 deficiency occurs in 10-28\% of uncomplicated pregnancies. ${ }^{3}$ Vitamin B12 can only be obtained from animal products. ${ }^{4}$ In pregnancy, B12 deficiency may go un-recognized if anemia is mistakenly attributed to other causes such as iron deficiency anemia/ physiologic hemodilution. Early detection of B12 deficiency is critical because when its severe deficiency goes untreated, it can have profound effects, including severe anemia, neural tube defects, low birth weights and finally intra-uterine deaths. ${ }^{5}$ It may also manifest with microangiopathic hemolytic anemias, low platelets, elevated liver enzymes, hyperbilirubinemia, mimicking HELLP/ partial HELLP syndrome. ${ }^{6}$
Most effective treatment method is through administering parenteral vitamin B12. About $20 \%$ of women show a physiologic drop in B12 levels during pregnancy, with lowest levels reached at third trimester. ${ }^{3,4}$ This physiologic fall is attributed to transfer of B12 to fetuse, hemodilution and change in $\mathrm{B} 12$ binders. However heightened suspicion is also warranted at risk pregnancies such as twin pregnancies with nutritional deficiency attributed to a strict vegetarian diet. Here we report a case of 32 years old lady with twin pregnancy at late gestation with severe anemia due to vitamin B12 deficiency.

\section{CASE REPORT}

A 32-year-old lady with BMI of 33, primigravida twin pregnancy at 35 weeks with hypothyroidism on thyroxin $50 \mathrm{microgm} /$ day with 2 days history of severe weakness, dyspnoea, giddiness, palpitation, epigastric pain and fever, 
was transferred from a local private clinic to our medical center. Prior to transfer she had normal BP, marked tachycardia (144/min) with notable laboratory evaluation for $\mathrm{Hb} 2.6 \mathrm{gm} / \mathrm{dl}$ and PCV 7.4\%. There, she was also evaluated for vomiting, abdominal pain and fever. Viral hepatitis, dengue serology, malarial parasites and other infectious diseases were negative on evaluation. She was also given $500 \mathrm{mg}$ ferrous carboxy maltose and 3 more unidentified injections. On arrival to our medical center her dietary history revealed pure vegetarian with main diets containing rice, bread, and green vegetables. On examination she was afebrile, pale, jaundice, non oedematous but normotensive with severe tachycardia peaked to $144 / \mathrm{min}$. On the day of admission her laboratory findings were $\mathrm{Hb} 5.7 \mathrm{gm} / \mathrm{dL}$, PCV 0.16, TLC 12600/mcL, platelet 50000/microL, SGOT 40 U/L, SGPT 23 U/L, ALP $165 \mathrm{IU} / \mathrm{L}, \mathrm{S}$ Bil $2.5 \mathrm{mg} / \mathrm{dL}$, LDH $1532 \mathrm{U} / \mathrm{L}$, UA $7.1 \mathrm{mg} / \mathrm{dL}$, $\mathrm{S}$ iron $408 \mathrm{mcg} / \mathrm{dL}$, TIBC $427 \mathrm{mcg} / \mathrm{dL}$, S. ferritin 304.3 $\mathrm{ng} / \mathrm{ml}$, and reduced haptoglobin $22 \mathrm{mg} / \mathrm{dL}$ on day 3 . Micro-spherocytes and erythroid precursors on peripheral blood smears suggested ongoing hemolysis. She also underwent panel study for autoimmune hemolysis and found to be normal.

Considering the fact that $20 \%$ of HELLP/partial HELLP syndrome occur in normotensive patients, these laboratory findings together with her clinical picture warranted the concern for the differential diagnosis of partial HELLP. Thyroxin was withdrawn in view of persisting tachycardia and 1-unit PRBC transfused. On second day she underwent USG (for liver span) and 2D Echo, which were normal. Her additional laboratory findings on peripheral blood smear revealed macro ovalocytes, tear drop cells, hyper-segmented nutrophils. These laboratory findings on peripheral smear with normal iron panel warranted further evaluation of folate and B12 level. Surprisingly B12 level was unusually high $(1754 \mathrm{pg} / \mathrm{ml})$ which could be explained by patient's history of the 3 unidentified injections that she received from local private clinic just 3 days prior to her transfer to our center. Blood transfusion was continued at $1 \mathrm{PRBC} /$ day on days 1, 2, 3, 5 and parenteral B12 1000 mcg was given on days 2, 4, 6 and 8, with gradual improvement in hematological parameters. Lab/treatment measures till delivery are in Table 1 and results of serial hematological parameters are depicted in Figure 1 and 2.

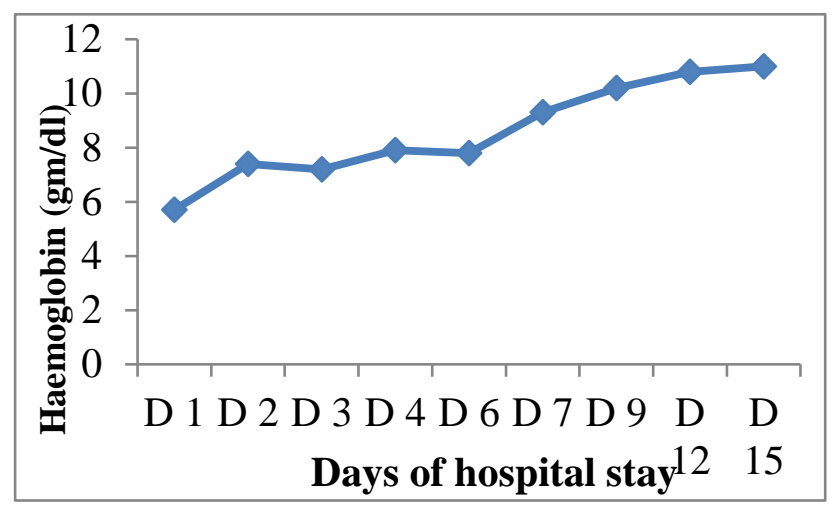

Figure 1: Hemoglobin while treatment till delivery.

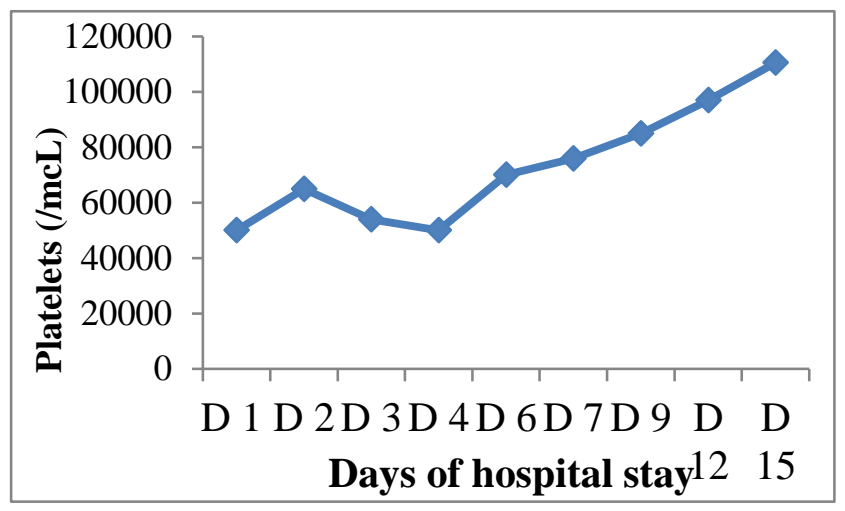

Figure 2: Platelets while treatment till delivery.

Table 1: Laboratory or treatment measures till delivery.

\begin{tabular}{|c|c|c|c|c|c|c|c|c|c|c|}
\hline $\begin{array}{l}\text { Lab or treatment } \\
\text { measures }\end{array}$ & D 1 & D 2 & D 3 & D 4 & D 5 & D 6 & D 7 & D 9 & D 12 & D 15 \\
\hline Hemoglobin (gm/dl) & 5.7 & 7.4 & 7.2 & 7.9 & - & 7.8 & 9.3 & 10.2 & 10.8 & 11 \\
\hline Platelet $(1000 / \mathrm{mcL})$ & 50 & 65 & 54 & 50 & - & 70 & 76 & 85 & 97 & 110.5 \\
\hline $\operatorname{MCV}(\mathbf{f l})$ & - & 106.5 & 101.1 & 98 & - & - & - & - & - & - \\
\hline Reticulocyte (\%) & - & & 3.3 & - & - & 5.1 & 12.5 & 10 & 7 & 5 \\
\hline Erythroid precursors & - & & + & + & - & - & - & - & - & - \\
\hline LDH (U/L) & 1532 & 1454 & 982 & NA & 965 & 703 & 585 & - & 310 & 170 \\
\hline Uric acid (mg/dL) & 7.1 & 7.6 & NA & NA & 10.4 & 10.3 & 10.2 & - & 7 & 4.5 \\
\hline Total bilirubin & 2.5 & 2.7 & NA & NA & 2.4 & 1.6 & 1.2 & - & 1.7 & 1.2 \\
\hline SGOT (U/L) & 40 & 43 & NA & NA & NA & 44 & 37 & 32 & 41 & 13 \\
\hline SGPT (U/L) & 23 & 18 & NA & NA & 36 & 26 & 34 & - & 188 & 26 \\
\hline Haptoglobin (mg/dl) & - & NA & 22 & NA & 33 & NA & NA & NA & NA & NA \\
\hline Urea (mg/dL) & - & 21 & NA & NA & 15 & 11 & 15 & NA & 15 & 10 \\
\hline Creatinine (mg/dl) & - & 0.6 & NA & NA & 0.7 & 0.5 & 0.5 & NA & 0.5 & 0.5 \\
\hline S. ferritin (ng/ml) & 304.3 & NA & NA & NA & NA & NA & NA & NA & NA & NA \\
\hline S. iron (mcg/dL) & 408 & NA & NA & NA & NA & NA & NA & NA & NA & NA \\
\hline TIBC (mcg/dL) & 427 & NA & NA & NA & NA & NA & NA & NA & NA & NA \\
\hline Vitamin B $12(\mathrm{pg} / \mathrm{ml})$ & 1754 & NA & NA & NA & NA & NA & NA & NA & 850 & NA \\
\hline
\end{tabular}


With further improvement in hematological and biochemical parameters, pregnancy was carried to term. Finally elective cesarean section was done on day 18 at 37 weeks 04 days and she delivered twin live babies weighing $2050 \mathrm{gm}$ and $1930 \mathrm{gm}$ but otherwise well at birth. The patient was discharged at home with a plan for continued vitamin B12 supplementation. On closed outpatient follow up both the babies had normal developmental milestones thereafter.

\section{DISCUSSION}

Vitamin B12 deficiency has foetal consequences includes growth retardation prematurity, intrauterine deaths, neural tube defects, and low birth weights. ${ }^{5}$ The only complication in our case was low birth weight, although it was twin delivery with babies' weight 2050 gm and 1930 gm which were below $10^{\text {th }}$ centile. Vitamin B 12 deficiency can cause anencephaly. Schorah et al found very low vitamin B12 levels in 3 anencephalic mothers compared with controls; this may be due to the fact that vitamin $\mathrm{B} 12$ is involved in the metabolism of neural tissues. $^{7}$ Bennett also found that severe vitamin B12 deficiency caused a high incidence of recurrent fetal loss. ${ }^{8}$

In 1982, Weinstein distinguished HELLP from preeclampsia for the first time. ${ }^{9}$ HELLP syndrome is characterized by hemolysis $(\mathrm{H})$, elevated liver enzymes (EL), and low platelets (LP). In our case laboratory findings suggested ongoing hemolysis and she also underwent panel study for autoimmune hemolysis and found to be normal. Laboratory findings together with her clinical picture warranted the concern for differential diagnosis of partial HELLP.

Pregnancy is compensated state and is associated with a steady and physiologic fall in serum vitamin B12. According to previous studies, vegetarian dietary habit was found to be a substantial risk factor for B12 deficiency. ${ }^{10-12}$ Vitamin B12 deficiency among pregnant women, who took vegetarian diet due to religious and socio-economic reasons, has been noted in literature. ${ }^{13}$ However, both vegans (whose diet contains no animal products) and vegetarians (diets containing dairy or eggs but no meat) have high rates of B12 deficiency. Our patient was totally a vegan whose main diet consisted of only rice, bread, and green vegetables. She had no appreciation of a balanced diet, including knowledge of different food groups. According to a study conducted by AIIMS, New Delhi in Haryana State, India, $74.1 \%$ of pregnant women had poor vitamin B12 stores. $^{13}$ Early diagnosis and management of vitamin B12 deficiency in third trimester of pregnancy can prevent the complications that are usually associated with this type of anemia. This study adds to the knowledge needed for inclusion of vitamin B 12 to the antenatal supplementation of pregnant women along with iron and folate. Megaloblastic anemia and HELLP syndrome can have similar presentation as depicted in our case, but have entirely different lines of management, so correct diagnosis becomes of utmost importance.

\section{CONCLUSION}

This case report demonstrates an unusual clinical misdiagnosis of HELLP syndrome in a patient with severe megaloblastic anemia. In such a case, an extensive laboratory workup with clinical suspicion for megaloblastic anemia should be performed. Also, our case emphasizes the importance of screening for B12 deficiency in pregnancy, especially in at-risk women (twin-pregnancy in pure vegetarian women) with unexplained anemia or thrombocytopenia.

\section{Funding: No funding sources \\ Conflict of interest: None declared \\ Ethical approval: Not required}

\section{REFERENCES}

1. Breymann C. Iron deficiency and anaemia in pregnancy: modern aspects of diagnosis and therapy. Blood Cells, Molecules Dis. 2002;29(3):506-21.

2. Molloy AM, Kirke PN, Brody LC, Scott JM, Mills JL. Effects of folate and vitamin B12 deficiencies during pregnancy on fetal, infant, and child development. Food Nutr Bull. 2008;29(2):S101-11.

3. Koebnick C, Heins UA, Dagnelie PC. Longitudinal concentrations of vitamin B12 and vitamin B12binding proteins during uncomplicated pregnancy. Clin Chem. 2002;48(6):928-33.

4. Milman N, Byg KE, Bergholt T, Eriksen L, Hvas AM. Cobalamin status during normal pregnancy and postpartum: a longitudinal study comprising 406 Danish women. Eur J Haematol. 2006;76(6):521-5.

5. Rogne T, Tielemans MJ, Chong MF. Association of maternal vitamin $b 12$ concentration in pregnancy with the the risk of preterm birth and low birth weight: a systematic review and meta-analysis of individual participant data. Am J Epidemiol. 2017;185(3):212-3.

6. Govindappagari S, Nguyen M, Gupta M, Hanna RM, Burwick RM. Severe Vitamin B12 Deficiency in Pregnancy Mimicking HELLP Syndrome. Case Rep Obstet Gynecol. 2019;2019:4325647.

7. Schorah CJ, Smithells RW, Scott J. Vitamin B12 and anencephaly. Lancet. 1980;1(8173):880.

8. Bennett M. Vitamin B12 deficiency, infertility and recurrent fetal loss. J Reprod Med. 2001;46(3):20912.

9. Weinstein L. Syndrome of hemolysis, elevated liver enzymes, and low platelet count: a severe consequence of hypertension in pregnancy. 1982. Am J Obstet Gynecol. 2005;193:859.

10. Herrmann W, Schorr H, Purschwitz K, Rasoul F, Richter V. Total homocysteine, vitamin B12, and total antioxidant status in vegetarians. Clin Chem. 2001;47(6):1094-101. 
11. Gilsing AM, Crowe FL, Lloyd-Wright Z, Sanders TA, Appleby PN, Aiien NE et al. Serum concentrations of vitamin B12 and folate in British male omnivores, vegetarians and vegans: results from a cross-sectional analysis of the EPIC- Oxford cohort study. Eur J Clin Nutr. 2010;64(9):933-9.

12. Pawlak R, Parrott SJ, Raj S, Cullum-Dugan D, Lucus D. How prevelent is vitamin B12 deficiency among vegetarians Nutr Rev. 2013;71(2):110-7.
13. Pathak P, Kapil U, Yajnik CS, Kapoor SK, Dwivedin $\mathrm{SN}$, Singh R. Iron, folate and vitamin B12 stores among pregnant women in a rural area of Haryana State, India. Food Nutr Bull. 2007;28(4):435-8.

Cite this article as: Singh SM, Thakur V, Singh PM. Severe megaloblastic anemia in twin pregnancy mimicking partial hemolysis, elevated liver enzymes and low platelet count syndrome: a case report. Int J Reprod Contracept Obstet Gynecol 2021;10:4581-4. 